\title{
Sex ratio and maternal rank in wild spider monkeys: when daughters disperse
}

\author{
M. McFarland Symington* \\ Department of Biology, Princeton University, Princeton, NJ 08544, USA \\ Received September 10, 1986/Accepted February 18, 1987
}

Summary. Data from a long-term field study of the spider monkey, Ateles paniscus, in Peru indicate that a strongly female-biased sex ratio exists from birth in this population. Of 46 infants born between July 1981 and June 1986, 12 were male, 32 were female and 2 were of undetermined sex. This effect is consistent between years as well, with more females than males born in each year of the study (Table 1). This bias is driven by the fact that low-ranking females produce daughters almost exclusively, while high-ranking females bias their investment somewhat less strongly towards sons (Table 2). The unusual pattern of female-biased maternal investment observed in this population of Ateles probably occurs for a combination of the following reasons: (1) maternal investment in individual male offspring is somewhat greater than in individual female offspring; (2) males remain with their natal groups, and the sons of high-ranking females are likely to be competitively superior to the sons of low-ranking females; (3) males compete for mates, and only the one or two most dominant males within a community are likely to achieve significant reproductive success. Two possible mechanisms of sex-ratio adjustment and the evidence for each are discussed.

\section{Introduction}

The question of adaptive sex ratio manipulation in mammals is a controversial one. There is little doubt that the ability to vary progeny sex ratio dependent upon maternal ability to invest and/or current environmental conditions would be of

\footnotetext{
* Current address: Evolution and Human Behavior Program, Rackham Building, University of Michigan, Ann Arbor, MI 48109 , USA
}

strong selective value, were it possible. Indeed, Williams (1979) found the lack of evidence for adaptive control of progeny sex ratio in mammals "rather mysterious". Since that time, however, several studies have presented convincing evidence of adaptive manipulation of the sex ratio in mammals (for review: Clutton-Brock and Albon 1982; Clutton-Brock and Iason 1986). In many of these studies, and particularly among primates, social rank has been found to be important in determining maternal investment patterns (Altmann 1980; Silk et al. 1981; Simpson and Simpson 1982, 1985; Meikle et al. 1984; Paul and Thommen 1984; Clutton-Brock et al. 1986). The primate species in which this relationship has been examined, however, have all been macaques and baboons, in which sons emigrate from their natal groups upon reaching sexual maturity, while daughters inherit their mother's rank. The social organization of spider monkeys is very different, with females emigrating from their natal groups upon reaching sexual maturity, while males remain at home to breed (McFarland Symington, in preparation). Highranking mothers in the macaques and baboons have most often been found to bias their investment towards daughters and/or low-ranking mothers to bias their investment towards sons (Altmann 1980; Silk et al. 1981; Simpson and Simpson 1982, 1985). Exactly the opposite pattern is seen in my data for Ateles paniscus.

\section{Methods \\ The data reported in this paper come from two undisturbed, habituated communities of spider monkeys in the vicinity of the Cocha Cashu Biological Station in the Manu National Park, southeastern Peru $\left(11^{\circ} 51^{\prime} \mathrm{S}, 71^{\circ} 19^{\prime} \mathrm{W}\right)$. The station is located in species-rich tropical moist forest (Holdridge 1967) with an annual rainfall of approximately $2000 \mathrm{~mm}$. A complete descrip- tion of the study site can be found elsewhere (Terborgh 1983).}


Spider monkeys are one of the largest New World primates, weighing up to $9 \mathrm{~kg}$ at maturity with males only slightly larger than females (Coelho et al. 1979). In Ateles, individuals travel in small parties of unstable membership. These parties are drawn from a larger, closed social unit known as the community (Klein and Klein 1977; Cant 1978; McFarland 1986). The community is analogous to the usual multi-male primate group but rarely, if ever, are all members of a community seen together.

I began an intensive investigation of the ecology and social organization of the Ateles population at Cocha Cashu in June 1982; 21 months over the subsequent 4 year period have been spent in direct observation of the two study groups. These two communities, comprising 31 adult females and 11 adult males, occupy an area of 375 hectares. The population density of Ateles at the site (excluding infants still being carried by their mothers) is approximately 25 individuals $/ \mathrm{km}^{2}$ (Terborgh 1983).

Individuals can be recognized through differences in facial and pelage characteristics, and infants can be reliably sexed as early as 1 day post-partum. Ages of those infants born up to one year prior to the onset of the study could be reliably estimated from pelage and behavior, and therefore these individuals are included in the births shown in Tables 1 and 2 for 1981-82.

Social rank was determined by the outcome of agonistic dyadic encounters, usually displacements involving an open mouth threat on the part of the dominant individual and retreat by the subordinate individual. I defined high-ranking females of those in the top half of the hierarchy, low-ranking females as those in the bottom half. There were no indications of nonlinearity and ranks were stable over the course of the study.

\section{Results}

Table 1 shows the numbers and sexes of infants born into the study population from July 1981-June 1986. As my 21 months of field work at Cocha Cashu were distributed discontinuously over the course of the study, it is possible that the female-biased infant sex ratio shown in Table 1 could have resulted from high perinatal mortality among male infants. A subsample of the data including only those births which occurred during a 13 month period when the two communities were under continuous observation (August 1984-August 1985) argues against this interpretation. Out of a total of 15 infants born, 5 were male, 9 were female, and one was of undetermined sex. Because of the highly dispersed nature of spider monkey social organization (Klein and Klein 1977; McFarland 1986), infants were frequently not observed until several days after their birth. However, all infants born during this 13 month interval were seen; late pregnancy is unmistakable in Ateles and no pregnancies were noted for which an infant was not subsequently observed. There is no significant difference between the proportion of males in the neonatal sample $(0.36)$ and either the proportion of male infants excluding the neonates $(0.23 ; G=$ $1.10, P>0.25)$, the proportion of males in the complete infant sample $(0.27 ; G=0.49, P>0.45)$ or the
Table 1. Sex ratios of Ateles paniscus born in the vicinity of the Cocha Cashu Biological Station, Peru, 1981-86

\begin{tabular}{llll}
\hline Year & M & F & $?$ \\
\hline $1981-82$ & 4 & 6 & 0 \\
$1982-83$ & 3 & 6 & 0 \\
$1983-84$ & 0 & 9 & 0 \\
$1984-85$ & 2 & 7 & 1 \\
$1985-86$ & 3 & 4 & 1 \\
\cline { 2 - 4 } Total & 12 & 32 & 2 \\
\hline
\end{tabular}

$\chi^{2}=9.09 ; P<0.005$

Table 2. Numbers of infants of each sex born to high- and low-ranking mothers, 1981-86

\begin{tabular}{|c|c|c|c|c|}
\hline \multirow[t]{3}{*}{ Year } & \multicolumn{4}{|c|}{ Rank } \\
\hline & \multicolumn{2}{|c|}{ High } & \multicolumn{2}{|c|}{ Low } \\
\hline & $\mathrm{M}$ & $\mathrm{F}$ & $\mathrm{M}$ & $\mathrm{F}$ \\
\hline $1981-82$ & 4 & 3 & 0 & 3 \\
\hline $1982-83$ & 3 & 3 & 0 & 3 \\
\hline $1983-84$ & 0 & 3 & 0 & 6 \\
\hline $1984-85$ & 2 & 1 & 0 & 6 \\
\hline 198586 & 3 & 1 & 0 & 3 \\
\hline Total & 12 & 11 & 0 & 21 \\
\hline
\end{tabular}

$\chi^{2}=15.07 ; P<0.001$

proportion of adult males in the population $(0.26$; $G=0.62, P>0.40)$. The consistent proportion of males in the neonate, infant and adult classes makes differential mortality of males an unlikely explanation for the observed sex ratio bias in this case. Direct evidence from juvenile mortality does not support higher early male mortality either. Of 8 individuals that died or disappeared prior to the age of 3 years, 2 were male, 5 female and 1 of undetermined sex.

Table 2 shows the relationship between a female's rank and the sex of her offspring for the same sample of infant births shown in Table 1. High- and low-ranking mothers differ significantly in the apportionment of their parental investment between male and female offspring. Low-ranking females are daughter specialists but high-ranking females seem to have equal numbers of sons and daughters. Only the highest-ranking females seem to bias their investment in favor of sons; out of 8 known offspring of the 4 top-ranked females, 6 were male.

Pre-weaning investment in individual male and female offspring appears to be unequal in this population of Ateles also. Among high-ranking females, the interval between the birth of male infant reared successfully to weaning and the birth of a 
subsequent infant is significantly longer than the interbirth interval following a female infant (36.0 vs 29.0 months; Mann-Whitney $U_{7,8}=12.5, P<$ $0.05)$. Two measures which may be more directly indicative of the amount a female is willing or able to invest in a particular infant are 1) the age to which she carries the infant before insisting that he or she begin to locomote independently and 2) the age to which she allows the infant to nurse ad libitum without any signs of conflict. I use this second measure in preference to the age at weaning itself since a female will continue to allow her previous infant to nurse from her until she is 23 months pregnant with the next, thus making this measure completely correlated with interbirth interval.

Among high-ranking females, mothers carry their male infants an average of 3 months longer than they carry their female infants, a difference which is significant despite the extremely small sample size ( 20.75 vs 17.3 months, $U_{3,4}=0, P<$ 0.03 ). The weaning conflict data also support the contention that females invest more in individual male vs. female offspring. High-ranking mothers begin to reject the nursing attempts of daughters almost four months earlier than those of sons, but this comparison fails to reach significance due to the small sample size ( 24.7 vs 28.4 months, $U_{3,5}=$ $3, P=0.128$ ).

However, it is instructive to note that there is no significant difference in the amount high- and low-ranking females invest in daughters by either of these two measures (weaning conflict: $24.7 \mathrm{vs}$ 22.75 months, $U_{3,4}=6, \quad P=0.571$; carrying: 17.3 vs 18 months, $U_{3,2}=3, P=0.60$ ). Thus, if we recalculate the above comparisons of maternal investment in sons and daughters including the daughters of low-ranking females, the larger sample size makes the pre-weaning investment bias towards sons even more pronounced (weaning conflict: 24.3 vs 22.5 months, $U_{3,6}=2, P<0.05$; carrying: 20.8 vs 17.7 months, $U_{4,6}=0.5, P<0.01$ ).

Post-weaning investment in males and females appears to be equal. Juveniles of both sexes continue to travel with their mother and share her core area until the age of approximately 4 years when females leave to begin visiting neighboring communities and males leave to begin traveling with the other adult males of their community (McFarland Symington, in preparation).

\section{Discussion}

Female-biased adult sex ratios are common in many group-living primate species (Clutton-Brock and Harvey 1977). In contrast, the sex ratio at birth in these same species has often been found to be male-biased, if any bias exists at all (van Schaik and van Noordwijk 1983). A numerical excess of females at birth appears to be rare in primates and among mammals in general (CluttonBrock and Albon 1982; Clutton-Brock 1982). In the Peruvian population of the spider monkey, Ateles paniscus, described above, females outnumber males by a ratio of almost $3: 1$. Unlike the situation in most other primates, however, data from my four-year field study indicate that this bias is present from birth. Similarly biased adult sex ratios, ranging from $26-36 \%$ male, have been found in all previous studies of Ateles (Carpenter 1935; Klein and Klein 1977; Cant 1978; van Roosmalen 1982). Unfortunately, in none of these studies were enough births recorded to comment on the infant sex ratio in these populations.

Several theories have been proposed to explain how observed deviations from the expected 1:1 sex ratio at birth might evolve. Unequal costs involved in the production of the two sexes (Fisher 1958), differential ability to invest on the part of the mother (Trivers and Willard 1973; Silk 1983), and local resource competition among progeny (Hamilton 1967; Clark 1978), have all been cited as possible causes of biased secondary sex ratios in mammalian populations. These hypotheses are not mutually exclusive and, in fact, each seems to have some applicability to the pattern of investment described here for Ateles.

Fisher (1958) proposed that if one sex were more costly to rear and/or produce than the other, it would be possible for total investment in males and females to be equal, even though a numerical bias existed. As has already been shown for some other polygynous mammals (Reiter et al. 1978; Clutton-Brock et al. 1981; Clutton-Brock et al. 1982), spider monkey mothers apparently invest more in individual male offspring than they do in individual female offspring. Interbirth intervals following a son are longer and these sons are weaned later and carried longer than daughters. Using the ratio of mean interbirth intervals following male and female infants, we can estimate that mothers invest $24 \%$ more in each male they rear to independence than they do in each female. If a mother invests 1 reproductive unit in each female infant and 1.24 reproductive units in each male infant, the proportion of reproductive units devoted to males in the sample of infants shown in Table 1 is still significantly different from one half (14.88 units for males: 32 units for females, $\chi^{2}=$ $6.25, P<0.02)$. It is clear that despite a higher per capita investment in males, total investment in males and females is not equal in this population. 
Trivers and Willard (1973) suggested that females should adjust the sex ratio of their offspring in accordance with their own ability to invest, i.e. those females in good condition and therefore capable of high levels of investment should overproduce that sex whose future reproductive success is most dependent upon maternal investment. In Ateles, there is a tendency for the top-ranked females to bias their investment toward sons ( 6 sons and 2 daughters, 7.44 vs 2 reproductive units, $\chi^{2}=$ $3.13, P<0.09)$ and it is clear that low-ranking females produce primarily daughters. This pattern of investment is consistent with Trivers and Willard's hypothesis if the benefits of high maternal rank disproportionately affect the reproductive success of sons over daughters in this population.

The evidence for this is still fragmentary at best since males and females of known maternal rank were just beginning to reach sexual maturity as of 1986. However, evidence from several sources indicates that the sons of high-ranking females benefit considerably more than their sisters (1) During the 4-5 years they spend in their natal community before emigrating, females do not inherit their mother's rank. Juvenile and subadult daughters of high-ranking females are routinely displaced by low-ranking adult females and I have never observed a mother to intervene on behalf of her daughter in such a situation. I have, on the other hand, seen a mother intervene on behalf of her son on several occasions, usually in the context of a play session which became overly rough. (2) High-ranking females participate in many more affiliative behaviors with the adult males of their community than do low-ranking females (McFarland Symington, in preparation) and therefore may be able to facilitate their sons' integration into the male hierarchy more effectively. (3) Body size, which has been found to be correlated with levels of maternal investment in other mammals (Reiter et al. 1978; Clutton-Brock et al. 1981; CluttonBrock et al. 1982), seems to be a more important determinant of rank in males than it is in females, as estimated visually in this population of Ateles. (4) Finally, although the exact relationship between dominance and reproductive success for male spider monkeys is as yet unknown, males do compete for mates and dominant males are able to monopolize estrous females better than subordinates (McFarland Symington, in preparation). In the chimpanzee, which has a very similar social organization but an apparently more egalitarian mating system, in which many males may copulate consecutively with a single estrous female, the adult (and, where available, infant) sex ratios seem more nearly equal than those found in Ateles (Nishida 1968; Kuroda 1979; Kano 1982; Goodall 1983; Hiraiwa-Hasegawa et al. 1984).

Clark (1978) proposed that females should adjust the sex ratio of their offspring to favor the dispersing sex because of reduced expected reproductive success among members of the philopatric sex through local resource competition. The fact that only the low-ranking females within this population of Ateles are biasing their investment towards the dispersing sex argues against Clark's hypothesis as originally formulated. Under certain circumstances, however, local resource/mate competition can result in differential investment by high- and low-ranking females. Silk (1983) has suggested that high-ranking females could, through harassment, enforce sex ratio adjustment on the part of low-ranking females in an attempt to minimize the competition for mates and resources that their offspring will later encounter as breeding adults within the group. The asymmetry in investment bias in Ateles, with low-ranking females showing a much stronger bias than high-ranking females, argues in favor of this view. If the probability of reproductive success for the sons of lowranking females were sufficiently low, either because of increased mortality as immatures or unsuccessful male-male competition as adults, there would be strong selection against low-ranking females giving birth to male infants at all. Indeed, local resource/mate competition could be the mechanism driving a Trivers-Willard response in this population of Ateles.

Two types of proximate mechanisms have been suggested to account for the skewed sex ratios that have been observed in mammals. Differential mortality (or motility) of $\mathrm{X}$ - and $\mathrm{Y}$-bearing spermatazoa would allow sex ratio to be adjusted prior to conception whereas differential mortality of male and female embryos in utero would modify the sex ratio after conception. If differential mortality of male embryos were responsible for the female biased sex ratios of low-ranking females in this population of Ateles, we might expect low-ranking females to have longer interbirth intervals than high-ranking females. Which is indeed what we find. Low-ranking females have a much longer interbirth interval than high-ranking females (using only those intervals following female births, 36.6 months vs 29.0 months, $U=16.5, P<0.06$ ). This finding obviously does not eliminate the possibility of a pre-conception mechanism since the longer interbirth interval of low-ranking females could be a result of their experiencing more infertile cycles before conceiving their predominantly 
female offspring. However, in light of the fact that differential male mortality in utero has already been demonstrated in several mammalian species, including humans (Robinette et al. 1957, Sundell 1962; Maurer and Foote 1971; McMillen 1979), the longer interbirth interval of low-ranking females in this population of spider monkeys suggests at least the possibility of post-conception sex ratio manipulation. Future sex ratio research must focus on the question of proximate mechanisms using experimental approaches with lab or semifree-ranging populations. Unfortunately, one likely triggering factor of sex ratio adjustment in wild populations, i.e. nutritional stress, may be difficult to accurately recreate in these captive studies.

Acknowledgements. I thank: J. Symington for his enthusiastic and unfailing field assistance, J. Seger and C.P. van Schaik for invaluable discussions, J. Brockmann, J. Terborgh, J. Ginsberg, D. Rubenstein and H. Horn for helpful comments on earlier drafts, and the Direccion General de Forestal y de Fauna, Lima, for permission to work in Manu. Financial support from the Organization of American States, World Wildlife Fund-US, and Princeton University is gratefully acknowledged.

\section{References}

Altmann J (1980) Baboon mothers and infants. Harvard University Press, Cambridge

Cant JGH (1978) Population survey of the spider monkey Ateles geoffroyi at Tikal, Guatemala. Primates 19:325-335

Carpenter CR (1935) Behavior of red spider monkeys in Panama. J Mammol 16:171-180

Clark $\mathrm{AB}$ (1978) Sex ratio and local resource competition in a prosimian primate. Science $201: 163-165$

Clutton-Brock TH (1982) Sons and daughters. Nature 298:11-13

Clutton-Brock TH, Albon SD (1982) Parental investment in male and female offspring in mammals. In: King's College Sociobiology Group (eds) Current problems in sociobiology. Cambridge University Press, Cambridge, pp 223-247

Clutton-Brock TH, Harvey PH (1977) Primate ecology and social organization. J Zool (Lond) 183:1-39

Clutton-Brock TH, Albon SD, Guiness FE (1981) Parental investment in male and female offspring in polygynous mammals. Nature 289:487-489

Clutton-Brock TH, Guiness FE, Albon SD (1982) Red deer. University of Chicago Press, Chicago

Clutton-Brock TH, Albon SD, Guiness FE (1986) Great expectations: dominance, breeding success and offspring sex ratios in red deer. Anim Behav 34:460-471

Coelho AM, Bramblett CA, Quick LB (1979) Activity patterns in howler and spider monkeys: an application of some sociobioenergetic methods. In: Bernstein IS, Smith EO (eds) Primate ecology and human origins. Garland, New York, pp 175-200

Dittus WPJ (1979) The evolution of behaviors regulating density and age-specific sex ratios in a primate population. Behaviour 69:265-301

Fisher RA (1958) The genetical theory of natural selection. Dover Publications, New York
Goodall J (1983) Population dynamics during a 15 year period in one community of free-living chimpanzees in the Gombe National Park, Tanzania. Z Tierpsychol 61:1-60

Hamilton WD (1967) Extraordinary sex ratios. Science $156: 477-488$

Hiraiwa-Hasegawa M, Hasegawa T, Nishida T (1984) Demographic study of a large-sized unit group of chimpanzees in the Mahale Mountains, Tanzania: a preliminary report. Primates 25:401-413

Holdridge LR (1967) Life zone ecology. Tropical Science Center, San Jose, Costa Rica

Kano T (1982) The social group of pygmy chimpanzees (Pan paniscus) of Wamba. Primates 23:171-188

Klein LL, Klein DB (1977) Feeding behaviour of the Colombian spider monkey. In: Clutton-Brock TH (ed) Primate ecology. Academic Press, London, pp 154-181

Kuroda S (1979) Grouping of the pygmy chimpanzees. Primates $20: 161-183$

Maurer RR, Foote RH (1971) Maternal aging and embryonic mortality in the rabbit. J Reprod Fertil 25:329-341

McFarland MJ (1986) Ecological determinants of fission-fusion sociality in Ateles and Pan. In: Lee PC, Else J (eds) Primate Ecology and Conservation. Cambridge University Press, Cambridge, pp 181-190

McMillen MM (1979) Differential mortality by sex in fetal and neonatal deaths. Science 204:89-91

Meikle DB, Tilford BL, Vessey SH (1984) Dominance rank, secondary sex ratio, and reproduction of offspring in polygynous primates. Am Nat 124:173-188

Nishida T (1968) The social group of wild chimpanzees in the Mahali Mountains. Primates 9:167-224

Paul A, Thommen D (1984) Timing of birth, female reproductive success and infant sex ratio in semifree-ranging Barbary macaques (Macaca sylvanus). Folia Primatol 42:2-16

Reiter J, Stinson NL, LeBoeuf BJ (1978) Northern elephant seal development : the transition from weaning to nutritional independence. Behav Ecol Sociobiol 3:337-367

Robinette WL, Geshwiler JB, Low JB, Jones DA (1957) Differential mortality by sex and age among mule deer. J Wildl Manage $21: 1-16$

van Roosmalen MGM (1982) Habitat preferences, diet, feeding behavior and social organization of the black spider monkey, Ateles paniscus paniscus in Surinam. Unpublished $\mathrm{PhD}$ thesis, University of Wageningen, Netherlands

van Schaik CP, van Noordwijk MA (1983) Social stress and the sex ratio of neonates and infants among non-human primates. Neth J Zool 33:249-265

Silk JB (1983) Local resource competition and facultative adjustment of sex ratios in relation to competitive abilities. Am Nat 121:56-66

Silk JB, Clark-Wheatley CB, Rodman PS, Samuels A (1981) Differential reproductive success and facultative adjustment of sex ratios among captive female bonnet macaques ( $\mathrm{Ma}$ caca radiata). Anim Behav 29:1106-1120

Simpson AE, Simpson MJA (1985) Short-term consequences of different breeding histories for captive rhesus macaque mothers and young. Behav Ecol Sociobiol 18:83-89

Simpson MJA, Simpson AE (1982) Birth sex ratios and social rank in rhesus monkey mothers. Nature $300: 440-441$

Sundell G (1962) The sex ratio before uterine implantation in the golden hamster. J Emb Exp Morph 10:58-63

Terborgh J (1983) Five New World primates. Princeton University Press, Princeton

Trivers RL, Willard DE (1973) Natural selection of parental ability to vary the sex ratio of offspring. Science 179:90-92

Williams GC (1979) The question of adaptive sex ratio in outcrossed vertebrates. Proc R Soc Lond B 205:567-580 